\title{
Dyslipidemia and Changes in Lipid Profiles Associated With Rheumatoid Arthritis and Initiation of Anti-Tumor Necrosis Factor Therapy
}

\author{
JEFFREY R. CURTIS, ${ }^{1}$ ANI JOHN, ${ }^{2}$ AND ONUR BASER ${ }^{3}$
}

Objective. To investigate the frequency of lipid testing in clinical practice and to explore the relationship between rheumatoid arthritis (RA), dyslipidemia, and other cardiovascular (CV) risk factors with RA treatment.

Methods. Patients in this retrospective database study were ages $\geq 18$ years and had $\geq 2$ physician diagnoses for $R A$ or osteoarthritis (OA; comparator group) between March 2004 and March 2008. Outcomes of interest included the percentage of RA and OA patients receiving lipid tests, lipid profiles (total cholesterol, low-density lipoprotein [LDL] cholesterol, and high-density lipoprotein [HDL] cholesterol) of RA versus OA patients, and lipid profiles of RA patients before and after initiation with a tumor necrosis factor (TNF) inhibitor. We used multivariable regression to control potential confounders between the cohorts.

Results. Over a median $\geq 2$-year followup, fewer RA patients than OA patients had $\geq 1$ lipid test $(62.0 \%$ [95\% confidence interval (95\% CI) 61.5-62.5] versus 69.8\% [95\% CI 69.5-70.1]). Mean total cholesterol and LDL cholesterol were each $4 \mathrm{mg} / \mathrm{dl}$ lower in the RA cohort $(P<\mathbf{0 . 0 0 0 1})$; HDL cholesterol was similar between the cohorts. Across the RA cohort, $\mathbf{2 5 . 2} \%$ of patients had suboptimal LDL cholesterol levels ( $\geq 130 \mathrm{mg} / \mathrm{dl}$ ). Among RA patients not receiving lipid-lowering therapy who initiated TNF inhibitor therapy $(n=96)$, mean total cholesterol and LDL cholesterol increased by 5.4 and $4.0 \mathrm{mg} / \mathrm{dl}$, respectively.

Conclusion. Patients with RA were less likely to be tested for hyperlipidemia and had more favorable lipid profiles than patients with OA. TNF inhibitor therapy modestly increased all lipid parameters. Additional studies are needed to determine the effect of traditional CV risk factors and inflammation and the impact of biologic agents on CV outcomes in RA patients.

\section{INTRODUCTION}

Patients with rheumatoid arthritis (RA) have higher rates of morbidity and mortality than the general population,

Supported by Genentech. Dr. Curtis's work was supported by grants from the NIH (AR-053351) and the Agency for Healthcare Research and Quality (R01-HS018517). STATinMED Research was supported by Roche/Genentech.

${ }^{1}$ Jeffrey R. Curtis, MD, MS, MPH: University of Alabama, Birmingham; ${ }^{2}$ Ani John, BSN, MPH: Genentech, South San Francisco, California; ${ }^{3}$ Onur Baser, MS, PhD: University of Michigan and STATinMED Research, Ann Arbor.

Dr. Curtis has received consultant fees, speaking fees, and/or honoraria (less than $\$ \mathbf{1 0 , 0 0 0}$ each) from UCB, Centocor, Pfizer, BMS, and Abbott, and (more than \$10,000 each) from Roche/Genentech, Consortium of Rheumatology Researchers of North America, Amgen, and Crescendo.

Address correspondence to Jeffrey R. Curtis, MD, MS, MPH, UAB Center for Education and Research on Therapeutics, University of Alabama at Birmingham, FOT 805D, 510 20th Street South, Birmingham, AL 35294. E-mail: jcurtis @uab.edu.

Submitted for publication September 8, 2011; accepted in revised form March 28, 2012. which is highly attributed to an increased risk of cardiovascular disease (CVD) among RA patients $(1,2)$. The increased risk of CVD appears to be linked to coronary atherosclerosis $(3,4)$ and may be directly caused by chronic inflammation or secondarily caused by physical inactivity and medications used to treat RA (5). Not surprisingly, RA treatment guidelines reflect this increased cardiovascular (CV) risk among patients with RA. Evidence-based and expert opinion-based recommendations from the European League Against Rheumatism for the screening and management of RA patients include annual CV risk assessment, management of identified CV risk factors, and aggressive suppression of the inflammatory process to further lower the CV risk (6).

Lipid levels appear to be altered as a result of RA disease activity. Data on total cholesterol and low-density lipoprotein (LDL) cholesterol levels in patients with RA are conflicting: some studies demonstrate similar (7) or lower (8) levels of total cholesterol, whereas others demonstrate increased levels of total cholesterol and LDL cholesterol in patients with early RA (9). Although reports on lipid profiles in RA patients vary, growing evidence suggests that 


\section{Significance \& Innovations}

- Our retrospective analysis of a representative US database demonstrated that patients with rheumatoid arthritis (RA) are significantly less likely to be tested for hyperlipidemia than controls (patients with osteoarthritis).

- Approximately $25 \%$ of patients with RA have suboptimal low-density lipoprotein cholesterol levels according to the Adult Treatment Panel III cholesterol management guidelines.

- Initiation of anti-tumor necrosis factor therapy increased total cholesterol levels by approximately $5 \mathrm{mg} / \mathrm{dl}$ among RA patients not receiving treatment with lipid-lowering agents.

patients with untreated RA have reduced total cholesterol, LDL cholesterol, and high-density lipoprotein (HDL) cholesterol levels $(8,10,11)$. Regardless of the total cholesterol changes in RA patients, several studies support the notion that RA leads to a more atherogenic lipid profile (ratio of total cholesterol to HDL cholesterol), which is correlated with disease activity and improves after treatment with antirheumatic medications $(7-9,12)$.

Inflammation is a common denominator in both RA and atherosclerosis. A growing body of evidence supports the involvement of common proinflammatory cytokines, such as macrophage migration inhibitory factor, interleukin-1 (IL-1), IL-6, and tumor necrosis factor $\alpha$ (TNF $\alpha)$, in the development and progression of both RA and atherosclerosis $(3,13)$. Several studies have demonstrated that the use of disease-modifying antirheumatic drugs and biologic agents that affect these cytokines reduces inflammation in patients with RA and may be associated with a reduced risk of CVD (12,14-20).

Given that inflammation in RA patients alters the lipid profile, it is not surprising that treatment to control inflammation in RA patients may also affect lipid levels. A recent meta-analysis of 24 observational studies evaluating the effect of TNF inhibitor therapy on lipids in patients with RA showed a small trend in an increase in total cholesterol, mostly due to an increase in HDL cholesterol levels (21). In light of uncertainties regarding the relationship between RA, lipid profiles, and potent antiinflammatory medications such as TNF inhibitor therapy, we used a large population-based database to investigate the frequency of lipid testing in clinical practice and to explore the relationship between RA, dyslipidemia, CVD risk factors, and RA treatment. The primary objective of this study was to evaluate the proportion of RA patients receiving lipid testing and the frequency of testing compared to controls (patients with osteoarthritis [OA]). We hypothesized that patients with RA would be tested less frequently than patients with OA. Secondary objectives included comparing lipid levels in RA patients versus controls (OA patients) among patients tested for hyperlipidemia and describing changes in lipid levels in patients with RA who initiated therapy with a TNF inhibitor.

\section{MATERIALS AND METHODS}

Patient identification. A retrospective analysis was conducted using data from the OptumInsight Impact database. This database includes medical claims, pharmacy claims, laboratory data, and patient eligibility data for 86.4 million covered patients, of which 63.7 million (74\%) have pharmacy benefits and 12.6 million have laboratory results. The database includes patients ages $\geq 65$ years, all of whom are covered by standard commercial or managed care plans. The Impact database is derived from 46 health plans located across all census regions in the US (predominantly located in the North, North Central, and Atlantic regions).

Patients were included in the study if they were age $\geq 18$ years and had $\geq 2$ separate physician diagnoses $(\geq 2$ months apart) for RA (International Classification of Diseases, Ninth Revision, Clinical Modification [ICD-9-CM] code 714.xx) or for OA (ICD-9-CM code 715.xx) between March 2004 and March 2008 (Table 1). Patients were excluded from the study if they had a diagnosis for any other autoimmune inflammatory disease at any time during the study observation period (see Supplementary Table 1, available in the online version of this article at http://online library.wiley.com/journal/10.1002/(ISSN)2151-4658). Patients with OA were chosen as a comparator group for patients with RA because OA is a chronic condition that affects joints and may limit physical functioning, but does not have the systemic inflammatory features more common to RA. Furthermore, OA patients were expected to be more comparable to RA patients, given a higher expected prevalence of use of nonsteroidal antiinflammatory drugs (a recognized CV risk factor that might impact CV risk assessment) and more frequent contact with the medical system (which can motivate more use of appropriate screening tests) compared to the general population without chronic medical conditions. Additional study eligibility requirements and study design details that varied by the 3 study objectives are listed in Table 1.

All measures of a complete lipid panel, i.e., total cholesterol, HDL cholesterol, LDL cholesterol, and triglycerides, that occurred at any time during the observation period were evaluated in this study in time windows specific for each objective (Table 1). Classification of lipid levels was based on the Adult Treatment Panel III (ATPIII) cholesterol management guidelines (22). Use of lipidlowering medications, including niacin, fibric acid derivatives, bile acid binding resins, cholesterol absorption inhibitors, and hydroxymethylglutaryl-coenzyme A reductase inhibitors, was also evaluated in this study.

Statistical analyses. All study variables, including baseline and outcome measures, were analyzed descriptively. Dichotomous variables were expressed as numbers and percentages and continuous variables were expressed as means \pm SDs, medians, or percentiles.

For dichotomous variables, $P$ values were calculated using the Mann-Whitney U test, and for continuous variables, $P$ values were calculated using $t$-tests. Multivariable 


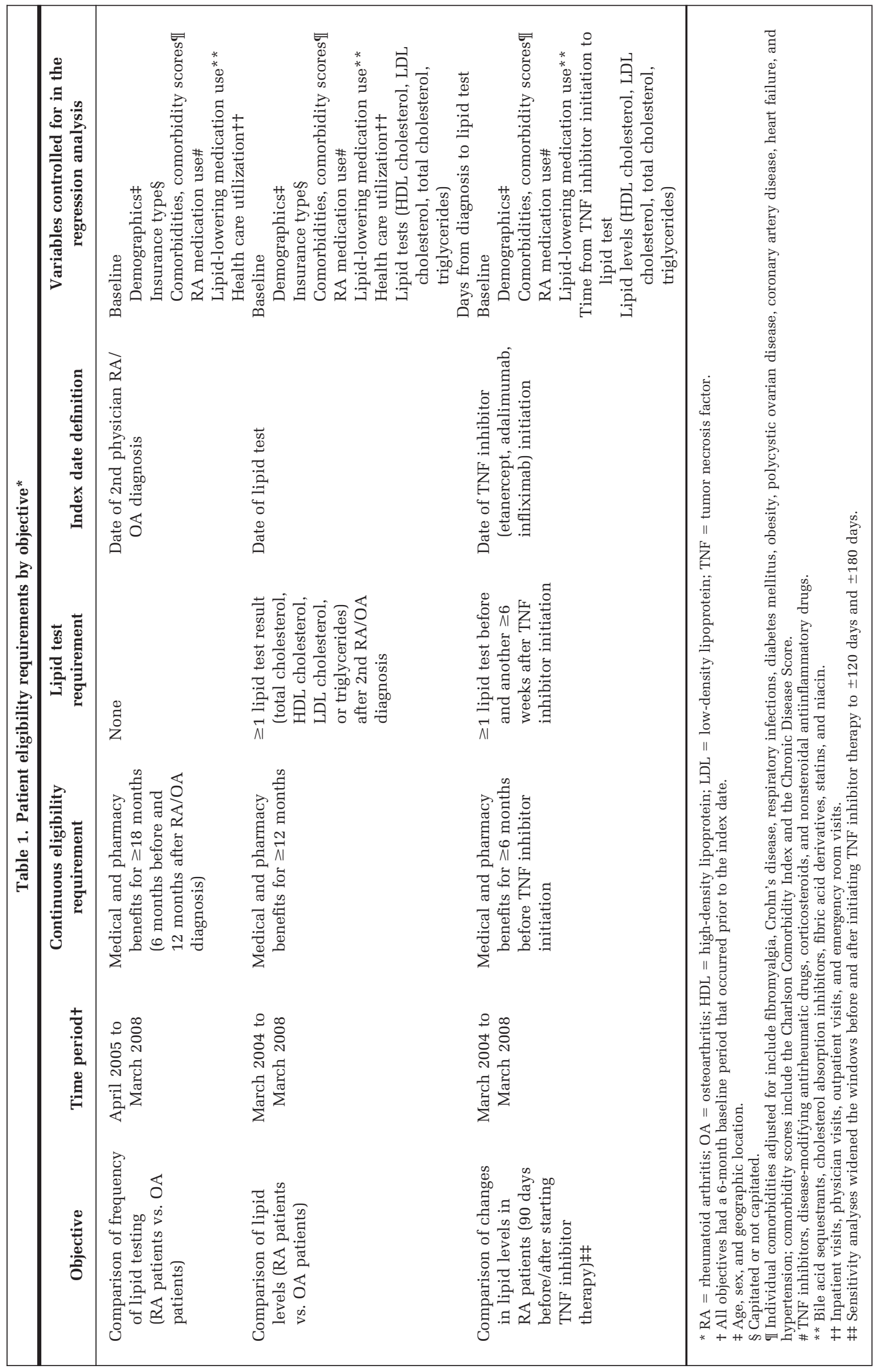


regression was used to control for confounders and to increase the efficiency of the estimators. The outcome variables and covariates used to control for baseline differences varied between objectives and are described in Table 1.

\section{RESULTS}

Objective 1: frequency of lipid testing, comparing RA versus $O A$ patients. The sample of individuals initially meeting eligibility requirements included 30,586 patients with an RA diagnosis and 107,534 patients with an OA diagnosis (control group). Characteristics of each group at baseline, defined as 6 months prior to RA or OA diagnosis, are shown in Table 2 . The groups were significantly different in most covariates; therefore, regression analysis was performed to control for these differences.

Over a median followup period of 2.2 years (interquartile range [IQR] 1.6-2.8 years) for patients in the RA group and 2.5 years (IQR 1.9-3.1 years) for patients in the OA group, fewer RA patients than OA patients had $\geq 1$ lipid test $(62.0 \%$ [95\% confidence interval (95\% CI) 61.5-62.5] versus $69.8 \%$ [95\% CI 69.5-70.1]). There were somewhat fewer patients in the RA group than in the OA group who had $\geq 1$ test for total cholesterol (59.8\% [95\% CI 59.360.3] versus 69.0\% [95\% CI 68.7-69.3]), HDL cholesterol (57.2\% [95\% CI 56.6-57.8] versus $66.4 \%$ [95\% CI $66.1-$ 66.7]), LDL cholesterol (58.6\% [95\% CI 58.0-59.2] versus $68.4 \%$ [95\% CI 68.1-68.7]), or triglycerides (59.1\% [95\% CI 58.5-59.7] versus 68.4\% [95\% CI 68.1-68.7]). Furthermore, the analysis of the risk-adjusted differences in the number of tests revealed that among patients who received a lipid test, slightly fewer tests were performed for RA patients than OA patients (total cholesterol: 2.0 [95\% CI 1.8-2.2] versus 2.9 [95\% CI 2.6-3.2], HDL cholesterol: 1.8 [95\% CI 1.7-1.9] versus 2.7 [95\% CI 2.5-2.9], LDL cholesterol: 1.9 [95\% CI 1.4-2.4] versus 2.9 [95\% CI 2.5-3.3], and triglycerides: 1.0 [95\% CI $0.8-1.2]$ versus 2.9 [95\% CI 2.7-3.2]). Because followup time was somewhat longer for OA patients versus RA patients, a subgroup analysis restricted the cohort to patients with $\geq 18$ months of observation time after the start of followup and fixed the ascertainment period to these 18 months. Among this subgroup (71\% of the RA cohort and $68 \%$ of the OA cohort), RA patients were less likely compared to OA patients to receive any total cholesterol testing (56\% [95\% CI 53-59] versus $67 \%$ [95\% CI 63-71]).

Objective 2: comparison of lipid levels in RA versus OA patients. From the initial sample size of 136,996 RA patients, and based on the availability of laboratory data in the database, $12,319(9.0 \%)$ were eligible for the lipid level objective analysis compared with the 29,621 patients (15.3\%) from the 194,192 OA controls. Similar to the study population for objective 1 , there were significant differences among eligible RA patients and OA patients at baseline (Table 3).

Multivariable-adjusted regression analysis was performed to assess risk-adjusted lipid levels and CVD-related

\begin{tabular}{|c|c|c|}
\hline & $\begin{array}{l}\text { RA patients } \\
(\mathrm{n}=30,586)\end{array}$ & $\begin{array}{l}\text { OA patients } \\
(\mathrm{n}=107,534)\end{array}$ \\
\hline Female sex & $22,658(74.1)$ & $62,689(58.3)$ \\
\hline \multicolumn{3}{|l|}{ Age group, years } \\
\hline $18-49$ & $13,883(45.4)$ & $27,430(25.5)$ \\
\hline $50-64$ & $13,560(44.3)$ & $58,716(54.6)$ \\
\hline $65-74$ & $2,124(6.9)$ & $12,289(11.4)$ \\
\hline $75-84$ & $1,019(3.3)$ & $9,099(8.5)$ \\
\hline Age, mean \pm SD years & $50.2 \pm 12.0$ & $56.1 \pm 10.6$ \\
\hline Capitated insurance & 7,683 (25.1) & $40,499(37.7)$ \\
\hline \multicolumn{3}{|l|}{ Census region } \\
\hline Midwest & $4,389(14.4)$ & $14,208(13.2)$ \\
\hline Northeast & $10,846(35.5)$ & $52,408(48.7)$ \\
\hline South & $11,778(38.5)$ & $30,069(28.0)$ \\
\hline West & $3,569(11.7)$ & $10,815(10.1)$ \\
\hline \multicolumn{3}{|l|}{ Comorbidities and scores } \\
\hline CCI score (45), mean \pm SD & $1.1 \pm 0.9$ & $0.4 \pm 0.9$ \\
\hline $\begin{array}{l}\text { Chronic Disease Score } \\
(46), \text { mean } \pm \text { SD }\end{array}$ & $2.5 \pm 3.0$ & $2.8 \pm 2.9$ \\
\hline Fibromyalgia & $2,593(8.5)$ & $5,336(5.0)$ \\
\hline Respiratory infections & $7,844(25.7)$ & $32,472(30.2)$ \\
\hline Diabetes mellitus & $1,880(6.2)$ & $10,385(9.7)$ \\
\hline Obesity & $664(2.2)$ & $4,445(4.1)$ \\
\hline Hypertension & $7,077(23.1)$ & $41,259(38.4)$ \\
\hline \multicolumn{3}{|l|}{$\begin{array}{l}\text { Health care utilization, } \\
\text { mean } \pm S D\end{array}$} \\
\hline Inpatient visits & $0.1 \pm 0.3$ & $0.1 \pm 0.3$ \\
\hline Physician visits & $4.4 \pm 6.2$ & $5.9 \pm 6.6$ \\
\hline Outpatient visits & $1.2 \pm 2.8$ & $1.7 \pm 3.4$ \\
\hline ER visits & $0.2 \pm 1.3$ & $0.3 \pm 1.3$ \\
\hline \multicolumn{3}{|l|}{ RA-related medications } \\
\hline Noncytotoxic DMARDst & $3,498(11.4)$ & $399(0.4)$ \\
\hline Cytotoxic DMARDs & $795(2.6)$ & $680(0.6)$ \\
\hline Methotrexate & $3,764(12.3)$ & $118(0.1)$ \\
\hline Corticosteroids & $7,421(24.3)$ & $16,772(15.6)$ \\
\hline NSAIDs & $13,047(42.7)$ & $50,215(46.7)$ \\
\hline Lipid-lowering medications & $3,570(11.7)$ & $26,896(25.0)$ \\
\hline \multicolumn{3}{|c|}{$\begin{array}{l}\text { * Values are the number (percentage) unless otherwise indicated. } \\
\text { RA = rheumatoid arthritis; OA = osteoarthritis; CCI = Charlson } \\
\text { Comorbidity Index; ER = emergency room; DMARDs = disease- } \\
\text { modifying antirheumatic drugs; NSAIDs = nonsteroidal antiinflam- } \\
\text { matory drugs. } \\
\text { † Gold compounds, penicillamine, chloroquine, hydroxychloro- } \\
\text { quine, and sulfasalazine. } \\
\text { f Azathioprine, cyclosporine, cyclophosphamide, and leflunomide. }\end{array}$} \\
\hline
\end{tabular}

comorbidity prevalence. Mean total cholesterol, LDL cholesterol, and triglyceride levels were significantly lower in the RA cohort than in the OA cohort (total cholesterol: $195 \mathrm{mg} / \mathrm{dl}$ [95\% CI 191-199] versus $199 \mathrm{mg} / \mathrm{dl}$ [95\% CI 192-205], LDL cholesterol: $112 \mathrm{mg} / \mathrm{dl}$ [95\% CI 111-113] versus $116 \mathrm{mg} / \mathrm{dl}$ [95\% CI 114-118], and triglycerides: $132 \mathrm{mg} / \mathrm{dl}$ [95\% CI 129-135] versus $138 \mathrm{mg} / \mathrm{dl}$ [95\% CI 136-140]; $P<0.0001$ for all comparisons), whereas HDL cholesterol levels were marginally higher for the RA cohort relative to the OA cohort ( $56.8 \mathrm{mg} / \mathrm{dl}$ versus $56.1 \mathrm{mg} /$ dl; $P=0.02$ ). Furthermore, significantly fewer RA patients than OA patients had borderline high or high total cholesterol and LDL cholesterol levels, based on ATP-III lipid 


\begin{tabular}{|c|c|c|}
\hline & $\begin{array}{l}\text { RA patients } \\
(\mathrm{n}=12,319)\end{array}$ & $\begin{array}{l}\text { OA patients } \\
(\mathrm{n}=29,621)\end{array}$ \\
\hline Female sex & $9,357(76.0)$ & $18,410(62.8)$ \\
\hline \multicolumn{3}{|l|}{ Age group, years } \\
\hline $18-49$ & $3,895(31.6)$ & $5,216(17.8)$ \\
\hline $50-64$ & $6,565(53.3)$ & $16,429(56.0)$ \\
\hline $65-74$ & $1,287(10.5)$ & $4,291(14.6)$ \\
\hline $75-84$ & $572(4.6)$ & $3,400(11.6)$ \\
\hline Age, mean \pm SD years & $54.2 \pm 11.0$ & $58.7 \pm 10.3$ \\
\hline Capitated insurance & $4,208(34.2)$ & $11,953(40.8)$ \\
\hline \multicolumn{3}{|l|}{ Census region } \\
\hline Midwest & $1,165(9.5)$ & $3,100(10.6)$ \\
\hline Northeast & $4,872(39.6)$ & $10,809(36.9)$ \\
\hline South & $5,595(45.4)$ & $13,981(47.7)$ \\
\hline West & $685(5.6)$ & $1,439(4.9)$ \\
\hline \multicolumn{3}{|l|}{ Comorbidities and scores } \\
\hline CCI score (45), mean \pm SD & $1.2 \pm 1.1$ & $0.5 \pm 1.0$ \\
\hline Chronic Disease Score (46), mean \pm SD & $4.5 \pm 3.5$ & $3.1 \pm 3.0$ \\
\hline Fibromyalgia & $912(7.4)$ & $1,262(4.3)$ \\
\hline Respiratory infections & $4,367(35.5)$ & $9,944(33.9)$ \\
\hline Diabetes mellitus & $1,599(13.0)$ & $4,242(14.5)$ \\
\hline Obesity & $330(2.7)$ & $1,295(4.4)$ \\
\hline Hypertension & $5,379(43.7)$ & $15,603(53.2)$ \\
\hline Polycystic ovarian disease & $18(0.2)$ & $12(0.0)$ \\
\hline Coronary artery disease & $943(7.7)$ & $2,538(8.7)$ \\
\hline Heart failure & $236(1.9)$ & $632(2.2)$ \\
\hline Hyperlipidemia & $6,073(49.3)$ & $16,635(56.7)$ \\
\hline \multicolumn{3}{|l|}{ Lipid levels, mean \pm SD mg/dl } \\
\hline Total cholesterol & $196.2 \pm 36.4$ & $198.7 \pm 37.8$ \\
\hline HDL cholesterol & $56.6 \pm 15.9$ & $55.2 \pm 16.1$ \\
\hline LDL cholesterol & $113.0 \pm 31.7$ & $115.9 \pm 33.3$ \\
\hline Triglycerides & $133.1 \pm 66.8$ & $138.5 \pm 68.8$ \\
\hline \multicolumn{3}{|l|}{ Health care utilization } \\
\hline Inpatient visits & $0.0 \pm 0.2$ & $0.1 \pm 0.3$ \\
\hline Physician visits & $4.2 \pm 6.0$ & $5.8 \pm 6.5$ \\
\hline Outpatient visits & $1.3 \pm 2.2$ & $1.8 \pm 3.5$ \\
\hline ER visits & $0.2 \pm 1.2$ & $0.3 \pm 1.2$ \\
\hline \multicolumn{3}{|l|}{ RA-related medications } \\
\hline DMARD only & $4,439(36.0)$ & $0(0.0)$ \\
\hline Non-TNF inhibitor only & $3(0.0)$ & $1(0.0)$ \\
\hline Non-TNF inhibitor and DMARDs & $13(0.1)$ & $0(0.0)$ \\
\hline TNF inhibitor only & $819(6.7)$ & $0(0.0)$ \\
\hline TNF inhibitor and DMARDs & $1,231(10.0)$ & $0(0.0)$ \\
\hline Corticosteroids & $4,166(33.8)$ & $4,587(15.6)$ \\
\hline NSAIDs & $6,639(53.9)$ & $12,849(43.8)$ \\
\hline Lipid-lowering medications & $3,294(26.7)$ & $8,678(29.6)$ \\
\hline \multicolumn{3}{|c|}{$\begin{array}{l}\text { * Values are the number (percentage) unless otherwise indicated. RA = rheumatoid arthritis; } \mathrm{OA}= \\
\text { osteoarthritis; CCI = Charlson Comorbidity Index; HDL = high-density lipoprotein; } \mathrm{LDL}=\text { low-density } \\
\text { lipoprotein; ER = emergency room; DMARD = disease-modifying antirheumatic drug; TNF = tumor } \\
\text { necrosis factor; NSAIDs = nonsteroidal antiinflammatory drugs. }\end{array}$} \\
\hline
\end{tabular}

classification levels ( $P \leq 0.0001)$ (Figure 1). Patients with RA were significantly less likely than patients with OA to have a recorded diagnosis of hyperlipidemia (33\% [95\% CI 28-35] versus 45\% [95\% CI 41-48]) and hypertension (45\% [95\% CI 41-49] versus 54\% [95\% CI 49-56]; $P<$ 0.0001 for both).

Objective 3: comparison of lipid levels before and after TNF inhibitor therapy in RA patients. A total of 1,393 patients with RA were eligible for the analysis of changes in lipid levels after TNF inhibitor therapy initiation. Of these patients, 289 had a lipid test within 90 days preceding and following TNF inhibitor initiation, 477 patients had a lipid test within 120 days, and 766 had a test within 180 days of TNF inhibitor initiation. Lipid test results were further stratified by use or nonuse of lipid-lowering medications before and after TNF inhibitor initiation. Patients were classified as consistent users (lipid-lowering medication use before and after TNF inhibitor therapy), nonusers (no lipid-lowering medication use before or after 


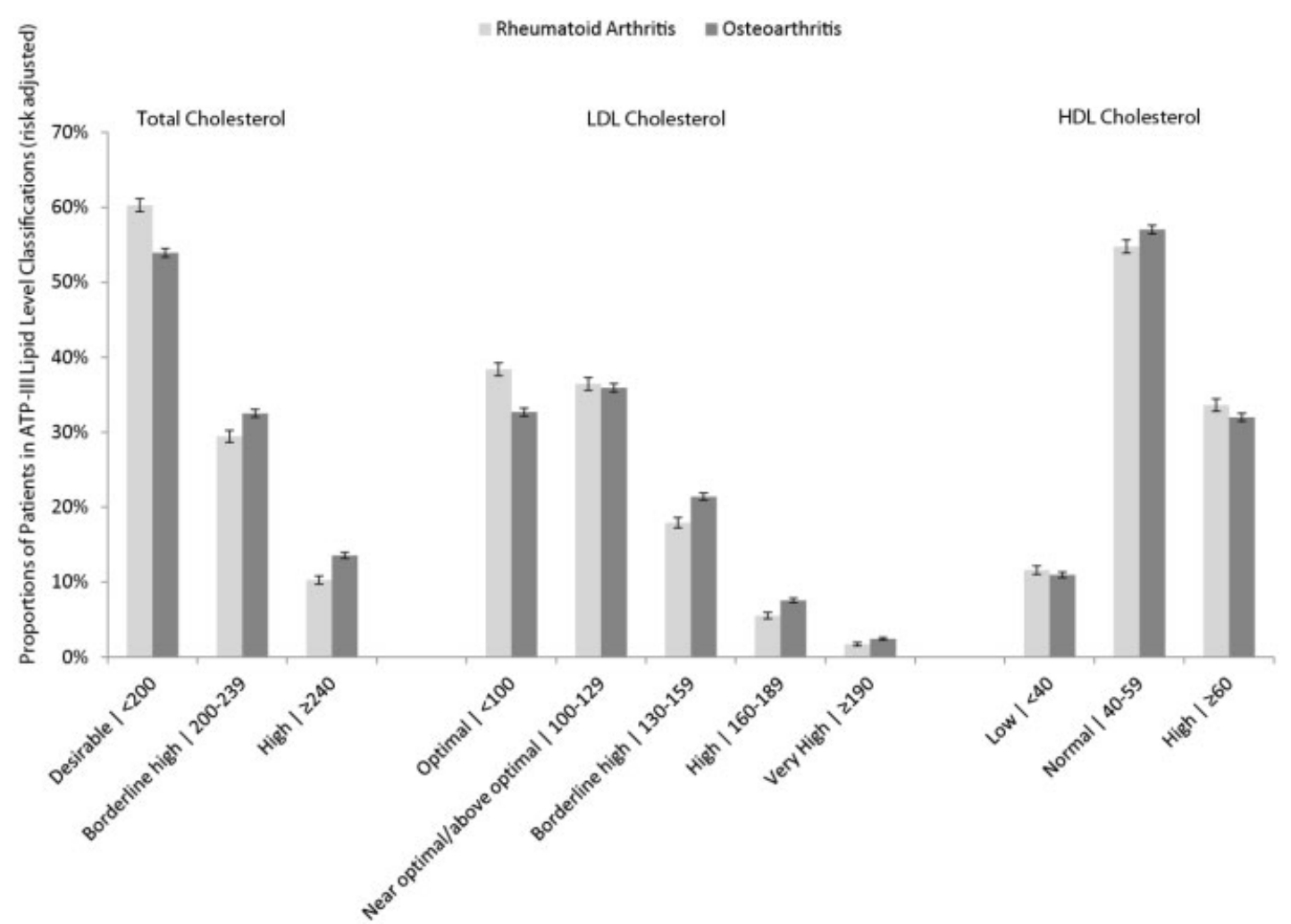

Figure 1. Proportions of rheumatoid arthritis (RA) and osteoarthritis (OA) patients in various lipid categories based on Adult Treatment Panel III (ATP-III) classifications. RA and OA cohorts were adjusted using multivariable regression based on factors listed in Table 1. Error bars show the $95 \%$ confidence interval of the mean. LDL = low-density lipoprotein; HDL = high-density lipoprotein.

- Patients not receiving lipid-lowering medications $\quad$-Patients receiving lipid-lowering medications

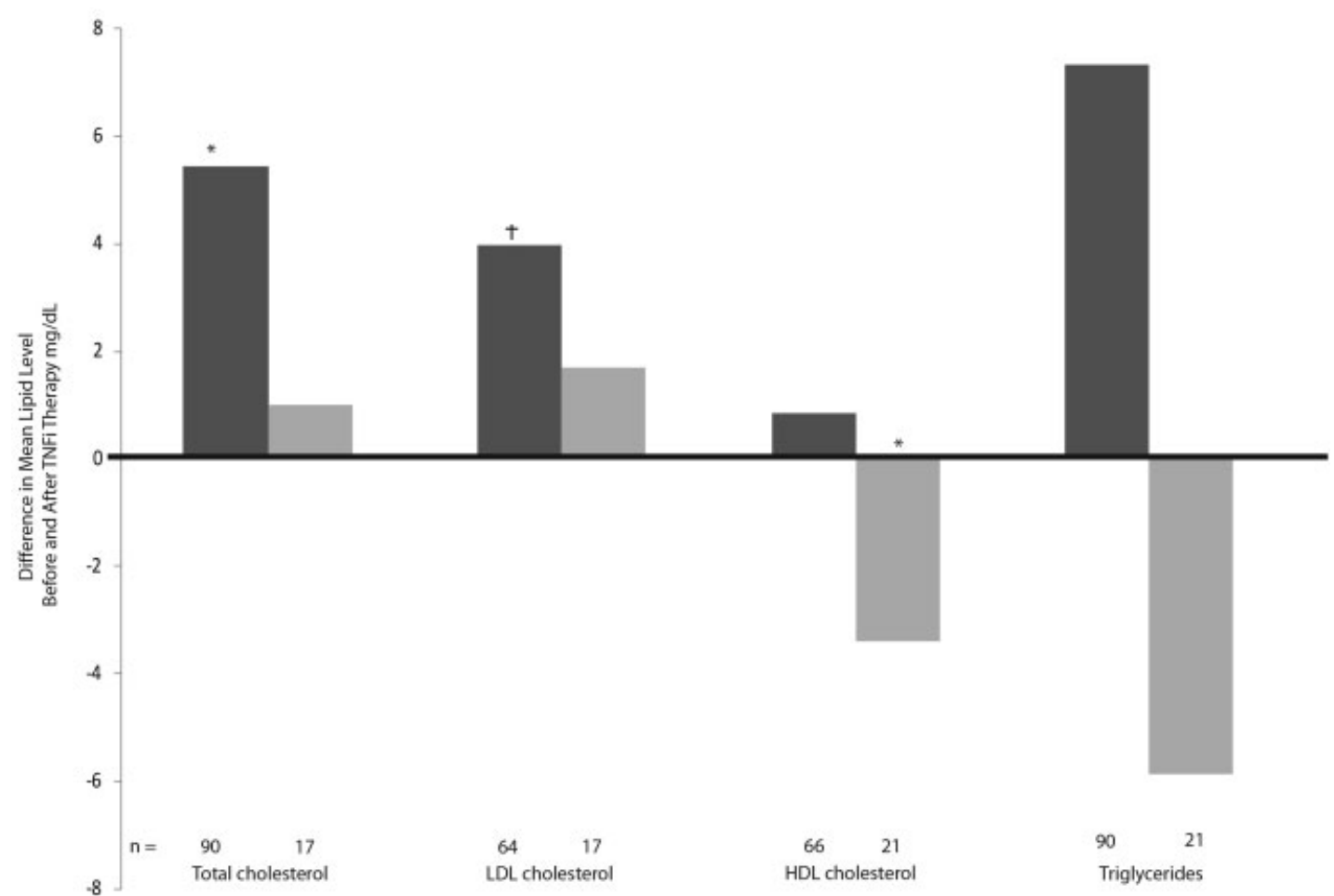

Figure 2. Changes in lipid levels after tumor necrosis factor inhibitor (TNFi) initiation in patients with rheumatoid arthritis. Includes patients who underwent lipid testing within 90 days before and after TNFi initiation. Not all patients underwent the complete set of lipid tests (e.g., patients might have undergone only total cholesterol testing but not high-density lipoprotein [HDL] cholesterol or low-density lipoprotein [LDL] cholesterol testing). A linear regression model was used to control for the factors listed in Table $1 .{ }^{*}=P \leq 0.0001 ;+t=$ $P \leq 0.01$ for the null hypothesis that there was no change in lipid values after TNFi initiation. 
TNF inhibitor therapy), or mixed users (lipid-lowering medication therapy either before or after TNF inhibitor therapy, but not both). Mixed lipid-lowering medication users' results were not reported due to an inadequate sample size to characterize the various patterns of use with these agents. Furthermore, we did not observe any patients who started TNF inhibitor therapy, then were tested for hyperlipidemia but who did not have a result available in the data, initiated a lipid-lowering medication, and then were retested and had lipid results available.

We identified 289 patients with paired lipid levels within \pm 90 days preceding and following the start of TNF inhibitor treatment (mean 65 days between the paired lipid tests). Among nonusers of lipid-lowering medications starting therapy with a TNF inhibitor $(\mathrm{n}=96)$, mean HDL cholesterol, total cholesterol, and LDL cholesterol levels increased modestly (HDL cholesterol: $0.9 \mathrm{mg} / \mathrm{dl}$ [95\% CI 0.1-1.6], total cholesterol: $5.4 \mathrm{mg} / \mathrm{dl}$ [95\% CI 2.6-18.3], and LDL cholesterol: $4.0 \mathrm{mg} / \mathrm{dl}$ [95\% CI $0.3-$ 7.7]) (Figure 2). Mean triglyceride levels also increased in these patients (mean change $7.3 \mathrm{mg} / \mathrm{dl} ; P=0.08$ ). Among consistent lipid-lowering medication users ( $\mathrm{n}=21$ ), HDL cholesterol levels decreased by a mean of $3.4 \mathrm{mg} / \mathrm{dl}$ (95\% CI 2.2-10.0); no significant changes were observed in total cholesterol, LDL cholesterol, and triglyceride levels (Figure 2). The atherogenic index (ratio of total cholesterol to HDL cholesterol) decreased in both patients consistently receiving and not receiving lipid-lowering medications (3.8 to 3.6 and 3.7 to 3.6 , respectively; $P=0.08$ ).

The within-person analysis described above was repeated for the groups who had lipid testing within \pm 120 and \pm 180 days of TNF inhibitor initiation. Study results were consistent, with adjusted LDL cholesterol levels consistently higher after TNF inhibitor initiation in patients not taking lipid-lowering medications, regardless of the timing of the test (data not shown).

\section{DISCUSSION}

This real-world analysis demonstrated that patients with RA had mean total cholesterol, LDL cholesterol, and triglyceride levels that were lower than patients with OA. Although RA patients were slightly more likely to be in a favorable ATP-III category, approximately $25 \%$ of RA patients had suboptimal lipid levels based on current ATP-III guidelines (22). Among patients with RA initiating TNF inhibitor therapy and who had their total cholesterol and LDL cholesterol levels retested within 3 months, mean total cholesterol and LDL cholesterol levels increased by 5 and $4 \mathrm{mg} / \mathrm{dl}$, respectively, after TNF inhibitor therapy was initiated. Finally, we observed that while patients with RA were only slightly less likely to receive any lipid testing than OA patients, approximately one-third of RA patients did not receive any testing during the observation period of more than 2 years.

Among RA patients not receiving lipid-lowering medications, we observed that treatment with a TNF inhibitor was associated with modest increases in total cholesterol and LDL cholesterol levels. This is consistent with results from other studies that observed increases in lipid levels after treatment with biologic agents. In a recent metaanalysis of 24 observational studies evaluating the effect of TNF inhibitor therapy on lipids in patients with RA, a small trend of an increase in total cholesterol was observed (21). Of the 4 controlled studies that measured the atherogenic index, 1 study found a significant increase of $8.9 \%$ in the TNF inhibitor therapy group and a significant decrease of $10.4 \%$ in the control group (23), 2 studies reported nonsignificant decreases in the TNF inhibitor group with no changes in the control groups $(24,25)$, and 1 study reported a significant decrease in cases compared to controls, but data were not provided (26). In our study, we found minimal changes in lipid profiles among RA patients who were treated with lipid-lowering medication prior to and during TNF inhibitor therapy. However, our results could not be compared with the meta-analysis, since no similar subgroup analysis of lipid level changes among patients receiving lipid-lowering medication treatments was performed (21).

Aside from TNF inhibitors, other biologic agents have been shown to affect lipid profiles. Tocilizumab (TCZ), which inhibits the proinflammatory cytokine IL-6 binding to its receptors (27), is associated with decreases in inflammatory markers (28). TCZ is associated with increased lipid levels in patients with RA (e.g., an increase in LDL cholesterol of $20 \mathrm{mg} / \mathrm{dl}$ among those receiving TCZ + methotrexate), but has not been associated with an increase in CV events during short-term followup (29-32). In a recently completed long-term followup study of TCZ in patients with RA (mean treatment duration 2.4 years), total cholesterol, HDL cholesterol, LDL cholesterol, and triglyceride levels increased after 6 weeks of treatment and remained relatively stable at the elevated level thereafter (31,32).

The clinical importance of lipid levels to CVD risk in RA is not completely understood. Recent evidence suggests that there may be a paradoxical effect of lipids on the risk of CVD in RA, where lower and not higher total cholesterol and LDL cholesterol levels are associated with an increased CV risk (11). Furthermore, although HDL cholesterol is generally considered to be cardioprotective, both through its ability to promote cholesterol efflux from artery cell walls and antiinflammatory properties that protect LDL cholesterol from oxidation, a growing body of evidence suggests that in inflammatory conditions such as RA and systemic lupus erythematosus, patients have nonprotective "proinflammatory HDL," which promotes accumulation of oxidized phospholipids in LDL cholesterol $(33,34)$.

Based on what appears to be more favorable total cholesterol and LDL cholesterol distributions in RA patients compared to OA patients, the results of this analysis suggest that lipid profiles in patients with RA only partially explain the previously observed excess CVD risk associated with the systemic inflammation of RA (35). Other inflammation-induced factors, such as increased oxidative stress, insulin resistance, endothelial dysfunction, prothrombotic state, and elevated homocysteine levels (36), as well as noninflammatory mechanisms, such as genetic polymorphism and CV toxicity associated with certain 
antirheumatic drugs (e.g., glucocorticoids), may also contribute to the increased CVD risk in RA (36).

A major strength of this study is that it is based on real-world clinical practice. The data set closely represents the US in terms of population age, sex, and geographic region (37). Comparing the US versus the Impact data set, the age distributions are as follows: $0-20$ years (27\% versus $25 \%$ ), 21-39 years (27\% versus 24\%), 40-64 years ( $31 \%$ versus $40 \%$ ), and $\geq 65$ years ( $13 \%$ versus $11 \%$ ). In terms of regions, the distributions are as follows: Northeast (18\% versus 29\%), Midwest (22\% versus 26\%), South (37\% versus $37 \%$ ), and West (23\% versus $11 \%$ ). Similar proportions of men are in each (49\% in the US versus $51 \%$ in the Impact data set).

Conclusions from this study need to be weighed within the confines of some limitations of this data source. Clinical data related to risk factors such as smoking, CVD history, family history of CVD, and blood pressure, as well as RA disease severity and activity, were not available in the database. Studies have shown that while some traditional risk factors (dyslipidemia, family cardiac history, hypertension, diabetes mellitus, and obesity) impart similar risk for a CV event among patients with or without RA, other traditional CV risk factors (male sex, smoking, and personal cardiac history) impart significantly less relative CV risk in patients with versus without RA (38). Beyond traditional CV risk factors, several disease severity and disease activity markers in RA, such as extraarticular manifestations, elevated erythrocyte sedimentation rate, rheumatoid factor seropositivity, higher joint count, and functional status, correlate with the rate of CVD and major CV events, including myocardial infarction, congestive heart failure, and death (4,39-41).

Another limitation of this study is that this analysis did not investigate longitudinal changes in lipid levels associated with TNF inhibitor therapy beyond 180 days. A study by Popa et al showed that although short-term effects of TNF inhibitor therapy on lipids seemed beneficial and antiatherogenic, the atherogenic index increased after 6 months from the start of therapy. Furthermore, changes in disease activity and inflammatory status were inversely correlated with changes in total cholesterol and HDL cholesterol levels and positively correlated with the variation of atherogenic index (42). When evaluated over a longer period of time, such as 6 months or beyond, infliximab treatment has been associated with significantly increased levels of total cholesterol and triglycerides, with no change in HDL cholesterol and LDL cholesterol or atherogenic indices at 6 months (43). In other studies, RA patients treated with infliximab had increased lipid levels (total cholesterol, HDL cholesterol, and LDL cholesterol) initially, which returned to baseline by 6 months to 1 year of treatment (except for total cholesterol levels, which remained increased in 1 study) $(26,44)$. The effect of time was partially addressed in this study by sensitivity analysis in which similar results were obtained when lipid tests were carried out before or after 120 and 180 days. However, further investigations into the long-term effect of TNF inhibitor therapy on lipid levels are needed. Finally, we excluded patients who initiated lipid-lowering therapy after initiation of TNF inhibitor therapy and before follow- up lipid testing was performed (i.e., described as "mixed" lipid-lowering medication users). While this may have excluded some individuals with elevated lipid levels, these patients initiated a lipid-lowering medication prior to followup lipid testing, avoiding concern for a selection bias related to the effect of TNF inhibitors on lipids.

In conclusion, patients with RA have a higher mortality rate than the general population. Much of this risk is due to CVD. This study showed that in clinical practice, RA patients were tested for dyslipidemia less frequently than their counterparts with OA. Furthermore, although patients with RA tended to have relatively lower lipid levels, more than $25 \%$ of patients had suboptimal lipid levels based on current ATP-III guidelines. Analysis of lipid levels in RA patients before and after TNF inhibitor therapy initiation showed modest increases in total cholesterol, LDL cholesterol, and HDL cholesterol levels among patients not receiving lipid-lowering medications. Due to the increased risk of CVD and mortality among patients with RA, more aggressive and earlier lipid management, including greater use of statin therapy, may be appropriate to reduce CVD among RA patients who have elevated lipid and C-reactive protein levels. Additional prospective longterm studies are needed to comprehensively determine the role of inflammation and the impact of biologic agents on lipid levels and CV outcomes in patients with RA.

\section{ACKNOWLEDGMENTS}

The authors would like to thank Kristin A. Hanson, PharmD, MS, and Jyoti S. Nandi, MD, PhD, who provided medical writing services on behalf of United BioSource Corporation, Bethesda, Maryland.

\section{AUTHOR CONTRIBUTIONS}

All authors were involved in drafting the article or revising it critically for important intellectual content, and all authors approved the final version to be published. Dr. Curtis had full access to all of the data in the study and takes responsibility for the integrity of the data and the accuracy of the data analysis.

Study conception and design. Curtis, John.

Acquisition of data. John.

Analysis and interpretation of data. Curtis, John, Baser.

\section{ROLE OF THE STUDY SPONSOR}

Genentech participated in the study design, data interpretation, and editing of the manuscript, and approved the content of the submitted manuscript. United BioSource Corporation participated in writing of the manuscript. Publication of this article was contingent on the approval of Genentech.

\section{REFERENCES}

1. Maradit-Kremers H, Crowson CS, Nicola PJ, Ballman KV, Roger VL, Jacobsen SJ, et al. Increased unrecognized coronary heart disease and sudden deaths in rheumatoid arthritis: a population-based cohort study. Arthritis Rheum 2005;52: 402-11.

2. Nicola PJ, Maradit-Kremers H, Roger VL, Jacobsen SJ, Crowson CS, Ballman KV, et al. The risk of congestive heart failure in rheumatoid arthritis: a population-based study over 46 years. Arthritis Rheum 2005;52:412-20.

3. Full LE, Ruisanchez C, Monaco C. The inextricable link be- 
tween atherosclerosis and prototypical inflammatory diseases rheumatoid arthritis and systemic lupus erythematosus. Arthritis Res Ther 2009;11:217.

4. Gabriel SE. Heart disease and rheumatoid arthritis: understanding the risks. Ann Rheum Dis 2010;69 Suppl:i61-4.

5. Turesson C, Jacobsson LT, Matteson EL. Cardiovascular comorbidity in rheumatic diseases. Vasc Health Risk Manag 2008;4:605-14.

6. Peters MJ, Symmons DP, McCarey D, Dijkmans BA, Nicola P, Kvien TK, et al. EULAR evidence-based recommendations for cardiovascular risk management in patients with rheumatoid arthritis and other forms of inflammatory arthritis. Ann Rheum Dis 2010;69:325-31.

7. Park YB, Lee SK, Lee WK, Suh CH, Lee CW, Lee CH, et al. Lipid profiles in untreated patients with rheumatoid arthritis. J Rheumatol 1999;26:1701-4.

8. Boers M, Nurmohamed MT, Doelman CJ, Lard LR, Verhoeven AC, Voskuyl AE, et al. Influence of glucocorticoids and disease activity on total and high density lipoprotein cholesterol in patients with rheumatoid arthritis. Ann Rheum Dis 2003; 62:842-5.

9. Georgiadis AN, Papavasiliou EC, Lourida ES, Alamanos Y, Kostara C, Tselepis AD, et al. Atherogenic lipid profile is a feature characteristic of patients with early rheumatoid arthritis: effect of early treatment. A prospective, controlled study. Arthritis Res Ther 2006;8:R82.

10. Choy E, Sattar N. Interpreting lipid levels in the context of high-grade inflammatory states with a focus on rheumatoid arthritis: a challenge to conventional cardiovascular risk actions. Ann Rheum Dis 2009;68:460-9.

11. Myasoedova E, Crowson CS, Kremers HM, Roger VL, FitzGibbon PD, Therneau TM, et al. Lipid paradox in rheumatoid arthritis: the impact of serum lipid measures and systemic inflammation on the risk of cardiovascular disease. Ann Rheum Dis 2011;70:482-7.

12. Van Halm VP, Nielen MM, Nurmohamed MT, van Schaardenburg D, Reesink HW, Voskuyl AE, et al. Lipids and inflammation: serial measurements of the lipid profile of blood donors who later developed rheumatoid arthritis. Ann Rheum Dis 2007;66:184-8.

13. Di Micco P, Ferrazzi P, Libre L, Mendolicchio L, Quaglia I, De Marco M, et al. Intima-media thickness evolution after treatment with infliximab in patients with rheumatoid arthritis. Int J Gen Med 2009;2:141-4.

14. Choi HK, Hernan MA, Seeger JD, Robins JM, Wolfe F. Methotrexate and mortality in patients with rheumatoid arthritis: a prospective study. Lancet 2002;359:1173-7.

15. Del Porto F, Lagana B, Lai S, Nofroni I, Tinti F, Vitale M, et al. Response to anti-tumour necrosis factor $\alpha$ blockade is associated with reduction of carotid intima-media thickness in patients with active rheumatoid arthritis. Rheumatology (Oxford) 2007;46:1111-5.

16. Naranjo A, Sokka T, Descalzo MA, Calvo-Alen J, HorslevPetersen K, Luukkainen RK, et al. Cardiovascular disease in patients with rheumatoid arthritis: results from the QUESTRA study. Arthritis Res Ther 2008;10:R30.

17. Wijbrandts CA, van Leuven SI, Boom HD, Gerlag DM, Stroes EG, Kastelein JJ, et al. Sustained changes in lipid profile and macrophage migration inhibitory factor levels after anti-tumour necrosis factor therapy in rheumatoid arthritis. Ann Rheum Dis 2009;68:1316-21.

18. Dixon WG, Watson KD, Lunt M, Hyrich KL, British Society for Rheumatology Biologics Register Control Centre Consortium, Silman AJ, et al, on behalf of the British Society for Rheumatology Biologics Register. Reduction in the incidence of myocardial infarction in patients with rheumatoid arthritis who respond to anti-tumor necrosis factor $\alpha$ therapy: results from the British Society for Rheumatology Biologics Register. Arthritis Rheum 2007;56:2905-12.

19. Listing J, Strangfeld A, Kekow J, Schneider M, Kapelle A, Wassenberg S, et al. Does tumor necrosis factor $\alpha$ inhibition promote or prevent heart failure in patients with rheumatoid arthritis? Arthritis Rheum 2008;58:667-77.

20. Reiss AB, Carsons SE, Anwar K, Rao S, Edelman SD, Zhang H, et al. Atheroprotective effects of methotrexate on reverse cholesterol transport proteins and foam cell transformation in human THP-1 monocyte/macrophages. Arthritis Rheum 2008; 58:3675-83.

21. Pollono EN, Lopez-Olivo MA, Lopez JA, Suarez-Almazor ME. A systematic review of the effect of TNF- $\alpha$ antagonists on lipid profiles in patients with rheumatoid arthritis. Clin Rheumatol 2010;29:947-55.

22. Third Report of the National Cholesterol Education Program (NCEP) Expert Panel. Detection, evaluation, and treatment of high blood cholesterol in adults (Adult Treatment Panel III): final report. Circulation 2002;106:3143-421.

23. Dahlqvist SR, Engstrand S, Berglin E, Johnson O. Conversion towards an atherogenic lipid profile in rheumatoid arthritis patients during long-term infliximab therapy. Scand J Rheumatol 2006;35:107-11.

24. Seriolo B, Paolino S, Ferrone C, Cutolo M. Effects of etanercept or infliximab treatment on lipid profile and insulin resistance in patients with refractory rheumatoid arthritis [letter]. Clin Rheumatol 2007;26:1799-800.

25. Seriolo B, Paoliono S, Ferrone C, Cutolo M. Comments on the original article by Soubrier et al: "effects of anti-tumor necrosis factor therapy on lipid profile in patients with rheumatoid arthritis" [letter]. Joint Bone Spine 2009;76:117-8; author reply 118.

26. Popa C, Netea MG, Radstake T, van der Meer JW, Stalenhoef $\mathrm{AF}$, van Riel PL, et al. Influence of anti-tumour necrosis factor therapy on cardiovascular risk factors in patients with active rheumatoid arthritis. Ann Rheum Dis 2005;64:303-5.

27. Mihara M, Kasutani K, Okazaki M, Nakamura A, Kawai S, Sugimoto M, et al. Tocilizumab inhibits signal transduction mediated by both mIL-6R and sIL-6R, but not by the receptors of other members of IL-6 cytokine family. Int Immunopharmacol 2005;5:1731-40.

28. Genovese MC, Smolen JS, Emery P, Jones G, Lee JS, Alecock $\mathrm{E}$, et al. Lipid and inflammatory biomarker profiles in patients receiving tocilizumab for rheumatoid arthritis: analysis of five phase 3 clinical trials [abstract]. Arthritis Rheum 2008;58 Suppl: S531-2.

29. Maini RN, Taylor PC, Szechinski J, Pavelka K, Broll J, Balint $\mathrm{G}$, et al, for the CHARISMA Study Group. Double-blind randomized controlled clinical trial of the interleukin-6 receptor antagonist, tocilizumab, in European patients with rheumatoid arthritis who had an incomplete response to methotrexate. Arthritis Rheum 2006;54:2817-29.

30. Nishimoto N, Hashimoto J, Miyasaka N, Yamamoto K, Kawai S, Takeuchi T, et al. Study of active controlled monotherapy used for rheumatoid arthritis, an IL-6 inhibitor (SAMURAI): evidence of clinical and radiographic benefit from an $\mathrm{x}$ ray reader-blinded randomised controlled trial of tocilizumab. Ann Rheum Dis 2007;66:1162-7.

31. Van Vollenhoven RF, Siri D, Furie R, Krasnow J, Alecock E, Alten R. Long-term safety and tolerability of tocilizumab treatment in patients with rheumatoid arthritis and a mean treatment duration of 2.4 years [abstract]. Arthritis Rheum 2009;60 Suppl:S731.

32. Van Vollenhoven R, Scali J, Curtis J, Krasnow J, Vernon E, Alten R. Safety of tocilizumab in patients with rheumatoid arthritis: analysis of median of 2.6 years of treatment in longtern extension studies [abstract]. Ann Rheum Dis 2010;69 Suppl:544.

33. Charles-Schoeman C, Watanabe J, Lee YY, Furst DE, Amjadi S, Elashoff D, et al. Abnormal function of high-density lipoprotein is associated with poor disease control and an altered protein cargo in rheumatoid arthritis. Arthritis Rheum 2009; 60:2870-9.

34. Hahn BH, Grossman J, Ansell BJ, Skaggs BJ, McMahon M. Altered lipoprotein metabolism in chronic inflammatory states: proinflammatory high-density lipoprotein and accelerated atherosclerosis in systemic lupus erythematosus and rheumatoid arthritis. Arthritis Res Ther 2008;10:213.

35. Dessein PH, Stanwix AE, Joffe BI. Cardiovascular risk in rheumatoid arthritis versus osteoarthritis: acute phase response related decreased insulin sensitivity and high-density lipo- 
protein cholesterol as well as clustering of metabolic syndrome features in rheumatoid arthritis. Arthritis Res 2002;4: R5.

36. Ku IA, Imboden JB, Hsue PY, Ganz P. Rheumatoid arthritis: model of systemic inflammation driving atherosclerosis. Circ J 2009;73:977-85.

37. Statistical abstract of the United States: 2000. 120th ed. Washington, DC: US Bureau of the Census; 2000.

38. Gonzalez A, Maradit Kremers H, Crowson CS, Ballman KV, Roger VL, Jacobsen SJ, et al. Do cardiovascular risk factors confer the same risk for cardiovascular outcomes in rheumatoid arthritis patients as in non-rheumatoid arthritis patients? Ann Rheum Dis 2008;67:64-9.

39. Avouac J, Allanore Y. Cardiovascular risk in rheumatoid arthritis: effects of anti-TNF drugs. Expert Opin Pharmacother 2008;9:1121-8.

40. Sokka T, Abelson B, Pincus T. Mortality in rheumatoid arthritis: 2008 update. Clin Exp Rheumatol 2008;26 Suppl: S35-61.

41. Solomon DH, Kremer J, Curtis JR, Hochberg MC, Reed G, Tsao $\mathrm{P}$, et al. Explaining the cardiovascular risk associated with rheumatoid arthritis: traditional risk factors versus markers of rheumatoid arthritis severity. Ann Rheum Dis 2010;69: 1920-5.

42. Popa C, van den Hoogen FH, Radstake TR, Netea MG, Eijsbouts AE, den Heijer M, et al. Modulation of lipoprotein plasma concentrations during long-term anti-TNF therapy in patients with active rheumatoid arthritis. Ann Rheum Dis 2007;66:1503-7.

43. Kiortsis DN, Mavridis AK, Filippatos TD, Vasakos S, Nikas $\mathrm{SN}$, Drosos AA. Effects of infliximab treatment on lipoprotein profile in patients with rheumatoid arthritis and ankylosing spondylitis. J Rheumatol 2006;33:921-3.

44. Peters MJ, Vis M, van Halm VP, Wolbink GJ, Voskuyl AE, Lems WF, et al. Changes in lipid profile during infliximab and corticosteroid treatment in rheumatoid arthritis. Ann Rheum Dis 2007;66:958-61.

45. Charlson ME, Pompei P, Ales KL, MacKenzie CR. A new method of classifying prognostic comorbidity in longitudinal studies: development and validation. J Chronic Dis 1987;40: 373-83.

46. Von Korff M, Wagner EH, Saunders K. A chronic disease score from automated pharmacy data. J Clin Epidemiol 1992;45: 197-203. 